\title{
Effects of sexualized video games on online sexual harassment
}

\author{
Jonathan Burnay ${ }^{1}$ (D) | Brad J. Bushman ${ }^{2}$ (D) | Frank Larøi ${ }^{1,3,4}$
}

${ }^{1}$ Psychology \& Neuroscience of Cognition Research Unit, Université de Liège, Liège, Belgium

${ }^{2}$ School of Communication and Department of Psychology, The Ohio State University, Columbus, Ohio

${ }^{3}$ Department of Biological and Medical Psychology, University of Bergen, Bergen, Norway

${ }^{4}$ NORMENT: Norwegian Centre of Excellence for Mental Disorders Research, University of Oslo, Oslo, Norway

\section{Correspondence}

Jonathan Burnay, Psychology \& Neuroscience of Cognition Research Unit, Université de Liège, Liège 4000 , Belgium.

Email: jonathan.burnay@uliege.be
Negative consequences of video games have been a concern since their inception. However, one under-researched area is the potential negative effects of sexualized video game content on players. This study analyzed the consequences of sexualized video game content on online sexual harassment against male and female targets. We controlled for a number of variables that might be related to online sexual harassment (i.e., trait aggressiveness, ambivalent sexism, online disinhibition). Participants $(N=211)$ played a video game with either sexualized or non-sexualized female characters. After gameplay, they had the opportunity to sexually harass a male or a female partner by sending them sexist jokes. Based on the General Aggression Model integrated with the Confluence Model of Sexual Aggression (Anderson \& Anderson, 2008), we predicted that playing the game with sexualized female characters would increase sexual harassment against female targets. Results were consistent with these predictions. Sexual harassment levels toward a female partner were higher for participants who played the game with sexualized female characters than for participants who played the same game with non-sexualized female characters. These findings indicate that sexualization of female characters in a video game can be a sufficient condition to provoke online sexual harassment toward women.

\section{KEYWORDS}

confluence model, general aggression model, objectification, sexual harassment, sexualization
"\#METOO:

If all the women who have been sexually harassed or assaulted wrote "Me too" as a status, we might give people a sense of the magnitude of the problem."

"There's too many incidents to put out here. Being told I must suck because I'm a girl, being told that I should be on my knees giving oral sex to my man because that's my place, being told that I should be in the kitchen making food for my man and not on WoW (World of Warcraft)"

\section{1 | INTRODUCTION}

The first quote was written on Twitter by Alyssa Milano. After that tweet, thousands of women used the hash tag \#MeToo as a way to denounce sexual harassment and assault. The second quote came from a female video game player in a study about gender harassment during a massively multiplayer online role playing game (Brehm, 2013).

In our society, sexual harassment is a serious problem faced by many women. Over 8 in 10 women have been sexually harassed or assaulted in their lifetime and 4 out of 10 women have experienced online sexual harassment (Stop Street Harassment, 2018). In particular, 
video game settings are hostile toward women (Gray, 2012; Salter \& Blodgett, 2012). A well-known example of online moral and sexual harassment from a video game community is the case of Anita Sarkeesian, who is a video-blogger that denounced sexism in video games in a video. After publishing her video, she received many death and rape threats, sexist insults, and pictures of her transformed into pornographic images. When women play video games, they are often the target of insults, sexist commentaries, and sexist (and even rape) jokes (Brehm, 2013; Tang \& Fox, 2016). All of these acts of behavior, even the more subtle ones such as offensive or sexist jokes, are considered forms of sexual harassment (McDonald, 2012; O'Hare \& O'Donohue, 1998; Pina \& Gannon, 2006). Sexual harassment refers to various forms of behavior that can be classified into three main categories: gender harassment, unwanted sexual attention, and sexual coercion (O'Hare \& O'Donohue, 1998; Pina \& Gannon, 2006). Gender harassment refers to a situation in which a person is subjected to offensive, gender-related, or sexual comments. Unwanted sexual attention refers to repeated attempts to establish a romantic relationship despite refusal, such as unwanted touching, sexual imposition, or assault. Sexual coercion refers to blackmail or rewards for sexual cooperation. However, it remains unclear what specific features of the video game environment contribute to online sexual harassment. One potential feature could be the sexualized content in some video games. In video games, female characters are often portrayed as sexualized. For example, they are often depicted with large breasts, small waists, a large amount of exposed skin, and revealing clothing (Beasley \& Collins Standley, 2002; Burgess, Stermer, \& Burgess, 2007; Downs \& Smith, 2010; Summers \& Miller, 2014). In theory, sexualized content in video games could increase sexual harassment.

\section{1 | Theoretical foundations of the present research}

Two theoretical models are especially relevant for explaining the shortterm impact of sexualized video games on sexual harassment, namely the General Aggression Model (GAM; Anderson \& Bushman, 2002) and the Confluence Model of Sexual Aggression (Malamuth, Linz, Heavey, Barnes, \& Acker, 1995; Vega \& Malamuth, 2007). In fact, both models have been integrated together (Anderson \& Anderson, 2008). Before describing the integrated model, we briefly describe each model separately.

In the General Aggression Model (GAM; Anderson \& Bushman, 2002) two types of input variables can influence aggression: (1) primary person variables; and (2) primary situation variables. Primary person variables include all the internal factors that can influence aggression. Primary situation variables include all the external factors that can influence aggression. Person and situation variables jointly influence the person's internal state, which includes aggressive thoughts, angry feelings, and physiological arousal (e.g., skin conductance, heart rate, blood pressure). Thus, there are three possible routes to aggression-through aggressive thoughts, angry feelings, and physiological arousal. However, the three routes are not mutually exclusive or even independent. For example, someone who has aggressive ideas might also feel angry inside and have elevated blood pressure. These internal states can influence appraisal and decision processes, such as whether ambiguous harmful behavior was intentional. The decisions and appraisals people make can influence their behavior, including whether they behave in an aggressive manner.

According to the Confluence Model of Sexual Aggression (Malamuth et al., 1995; Vega \& Malamuth, 2007), two main paths can facilitate sexual aggression: (1) "impersonal sex" and (2) "hostile masculinity." Impersonal sex is characterized by a promiscuous, noncommittal, game-playing orientation toward sexuality. Hostile masculinity is a personality profile that combines insecurity, hostility, and distrust, especially toward women.

The Confluence Model of Sexual Aggression, when integrated with the GAM (Anderson \& Anderson, 2008), adds several specific individual differences as predictors of sexual aggression by creating hostile thoughts or feelings toward women (Figure 1). Two individual differences that appear to be particularly relevant to sexual harassment are trait aggressiveness (Coombs \& Holladay, 2004; Thompson \& Morrison, 2013) and ambivalent sexism (LeMaire, Oswald, \& Russell, 2016; Russell \& Oswald, 2016). The present research includes measures of both of these variables.

Three other more specific theoretical models are also relevant to the present research because they explain the creation of preexisting knowledge structures relevant to sexual harassment and sexualized video games: (1) Expectation State Theory (Berger, Cohen, \& Zelditch, 1972); (2) Social Cognitive Theory of Gender Development and Differentiation (Bussey \& Bandura, 1999), and (3) Objectification Theory (Fredrickson \& Roberts, 1997). According to Expectation State Theory, cultural norms dictate how men and women are supposed to act. Cultural norms help people anticipate the behavior of others during social interactions. In many societies, women still possess a

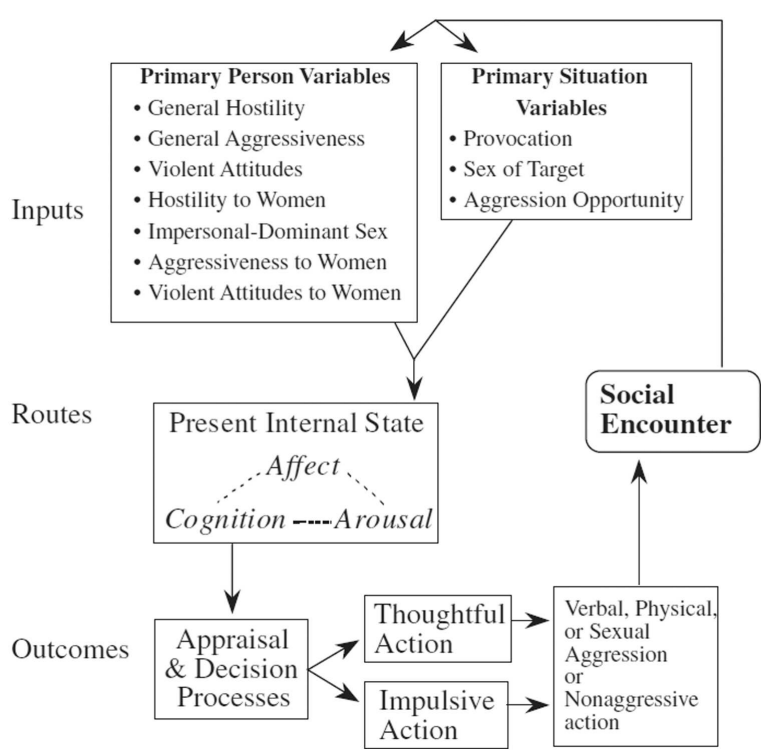

FIGURE 1 Integrated Confluence Model of Sexual Aggression and General Aggression Model (Anderson \& Anderson, 2008) 
lower status than men. Therefore, women are expected to act in a submissive and nonaggressive manner, whereas men are expected to act in a dominant and aggressive manner. In addition, the more men conform to these cultural norms, the more likely they are to sexually harass women (Pryor, 1987; Sinn, 1997).

Cultural norms about males and females can be learned by observing real people and by observing media characters, such as those in video games. The present research used sexualized video games to convey cultural norms about women. According to Social Cognitive Theory of Gender Development and Differentiation (Bussey \& Bandura, 1999), media messages can influence gender-based attitudes and behavior. In video games, most of the main characters are men (Dill \& Thill, 2007; Miller \& Summers, 2007). In addition, most video games are created by men (Australian Bureau of Statistics, 2017), and are designed to appeal to heterosexual males (Shaw, 2011; Williams, Martins, Consalvo, \& Ivory, 2009). Video games often convey messages about male dominance and female submissiveness (Dill \& Thill, 2007; Jansz \& Martis, 2007; Miller \& Summers, 2007; Summers \& Miller, 2014).

In addition, many video games that contain female characters sexually objectify them (Lynch, Tompkins, van Driel, \& Fritz, 2016; Summers \& Miller, 2014). Sexual objectification occurs when a person's body parts or functions are separated from the person, reduced to the status of instruments, or regarded as capable of representing the entire person (Gervais, Bernard, Klein, \& Allen, 2013). According to Objectification Theory (Fredrickson \& Roberts, 1997), sexual objectification is a form of gender oppression. Further, sexual objectification is a specific case of dehumanization, which is described as a process in which a person is denied their humanness (e.g., treated like animals or objects; Bernard, Gervais, Allen, Delmée, \& Klein, 2015). The more a person sexually objectifies and dehumanizes women, the more likely that person is to accept attitudes toward sexual harassment (Rudman \& Mescher, 2012).

Within these theories, sexual harassment, male dominance, female submissiveness, and sexual objectification seem to be interrelated concepts. Such preexisting knowledge structures can be brought to a social encounter by an individual before they even play a video game. During gameplay, sexualized images can prime or activate concepts related to sexual harassment in the minds of game players.

Collectively, these theories provide a firm foundation for the present research. Based on these theories, the present study tests the hypothesis that exposure to sexualized female video game characters will increase sexual harassment toward real females.

\subsection{Objective of the present research}

The objective of the present study was to determine the effect that playing a sexualized video game has on online sexual harassment behavior. Previous research has shown that sexualized content of video games can increase tolerance of sexual harassment (Dill, Brown, \& Collins, 2008; Driesmans, Vandenbosch, \& Eggermont, 2015; Yao, Mahood, \& Linz, 2010). However, considering our specific objective, we made three changes from previous studies.
First, we had participants actually play a sexualized video game. For example, participants in one study were only exposed to screen shots of sexualized avatars (Dill et al., 2008). Second, we experimentally manipulated sexualization (i.e., wearing revealing clothes and exposing a large amount of skin vs. wearing modest clothing with little skin exposed). In previous studies, sexualization is often confounded with other factors. For example, participants in one study played either a neutral video game or a sexualized video game that contained other confounding factors, namely, sexuality (i.e., presence of a sexual act) and sexism (i.e., negative remarks about women, Yao et al., 2010). Such a design makes it impossible to isolate the influence of only one of these features on sexual harassment. Third, we used a measure of observable behavior of sexual harassment. Previous studies have used measures of attitudes toward sexual harassment (Dill et al., 2008; Driesmans et al., 2015; Yao et al., 2010). Fourth, we controlled for several individual variables such as trait aggressiveness and sexism, as suggested by the Confluence Model of Sexual Aggression. Further, online disinhibition may be a specific predictor of sexual harassment in an online video game environment. Online interactions are easily disinhibited due to structural characteristics such as anonymity and perceived lack of repercussions for antisocial behavior (Udris, 2014). By controlling for these individual differences, we can better isolate the impact of sexualized video games on sexual harassment.

Our first hypothesis is that the level of online sexual harassment behavior, especially toward women, will increase after playing a sexualized video game (i.e., we expected a two-way Sexualization $X$ Partner Gender interaction). Furthermore, based on previous research (Dill \& Thill, 2007; Yao et al., 2010) and based on the Confluence Model of Sexual Aggression (Malamuth et al., 1995; Vega \& Malamuth, 2007), our second hypothesis is that male players should be more likely than female players to sexually harass a real female after playing a sexualized video game (i.e., we expected a three-way Sexualization $X$ Partner Gender X Participant Gender interaction).

\section{2 | METHOD}

\section{1 | Participants}

Participants were 211 students (49\% male) 18 to 37 years old $(M=21.87, S D=2.94)$ recruited from a Belgian university. Among the 211 participants, 114 identified themselves as video game players, and spent between 0 and $60 \mathrm{hr}$ per week playing video games ( $M=11.35$, $S D=11.43$ ). None of the participants had previously played the video game used in the present study. ${ }^{1}$

\section{2 | Materials}

\subsection{1 | Video game}

All participants played the same video game (Ultra Street Fighter IV). Sexualization was manipulated by changing the outfit of the characters 
(Figure 2). In the highly sexualized condition, both characters wore a revealing swimsuit, whereas in the non-sexualized condition, both characters wore non-revealing outfits.

\subsection{2 | Sexual harassment task}

The sexual harassment task was similar to the computer harassment task used in previous studies (Galdi, Maass, \& Cadinu, 2014; Siebler, Sabelus, \& Bohner, 2008), except that sexist jokes instead of pornographic images were sent to a partner. This measure of behavioral sexual harassment has been validated previously (Tang, 2016). In this task, participants were presented with 16 PowerPoint slides. Each slide contained a pair of jokes written in French. Odd-numbered slides contained two nonsexist jokes (e.g., "Why do sharks swim in salt water? Because pepper would make them sneeze!"), and even-numbered slides contained one sexist joke and one nonsexist joke. Sexist jokes were gender specific. That is, female sexist jokes were used for female partners (e.g., "Why is it called PMS? Because 'Mad Cow Disease' was already taken."), whereas male sexist jokes were used for male partners (e.g., "What do you call a man who has lost his intelligence? A widower").
Participants had to decide which of the two jokes to send their partner using a Skype chat.

The measure of online sexual harassment was the number of sexist jokes the participant sent to their partner, which could range from 0 to 8. When the participant sent their partner a sexist joke, the partner sent a negative scripted response (e.g., "I don't like this joke"), and these responses became more negative every time a new sexist joke was sent (e.g., "This joke is disgusting"). When the participant sent the partner a non-sexist joke, the partner sent a positive scripted response (e.g., "lol ^^^", "Haha, not bad!").

Sexist jokes were chosen to be hostile and critical of a person based on their gender, whereas non-sexist jokes did not mention a person's gender. Both sexist and non-sexist jokes were chosen to be humorous. All jokes were translated from previously-used English jokes (Tang, 2016), except for jokes that did not make sense in French. A pilot study showed that the jokes within each pair did not differ in terms of how humorous they were, that sexist jokes were rated as more sexist than nonsexist jokes, and that male and female sexist jokes did not differ in terms of how sexist they were (see Supplementary Materials).
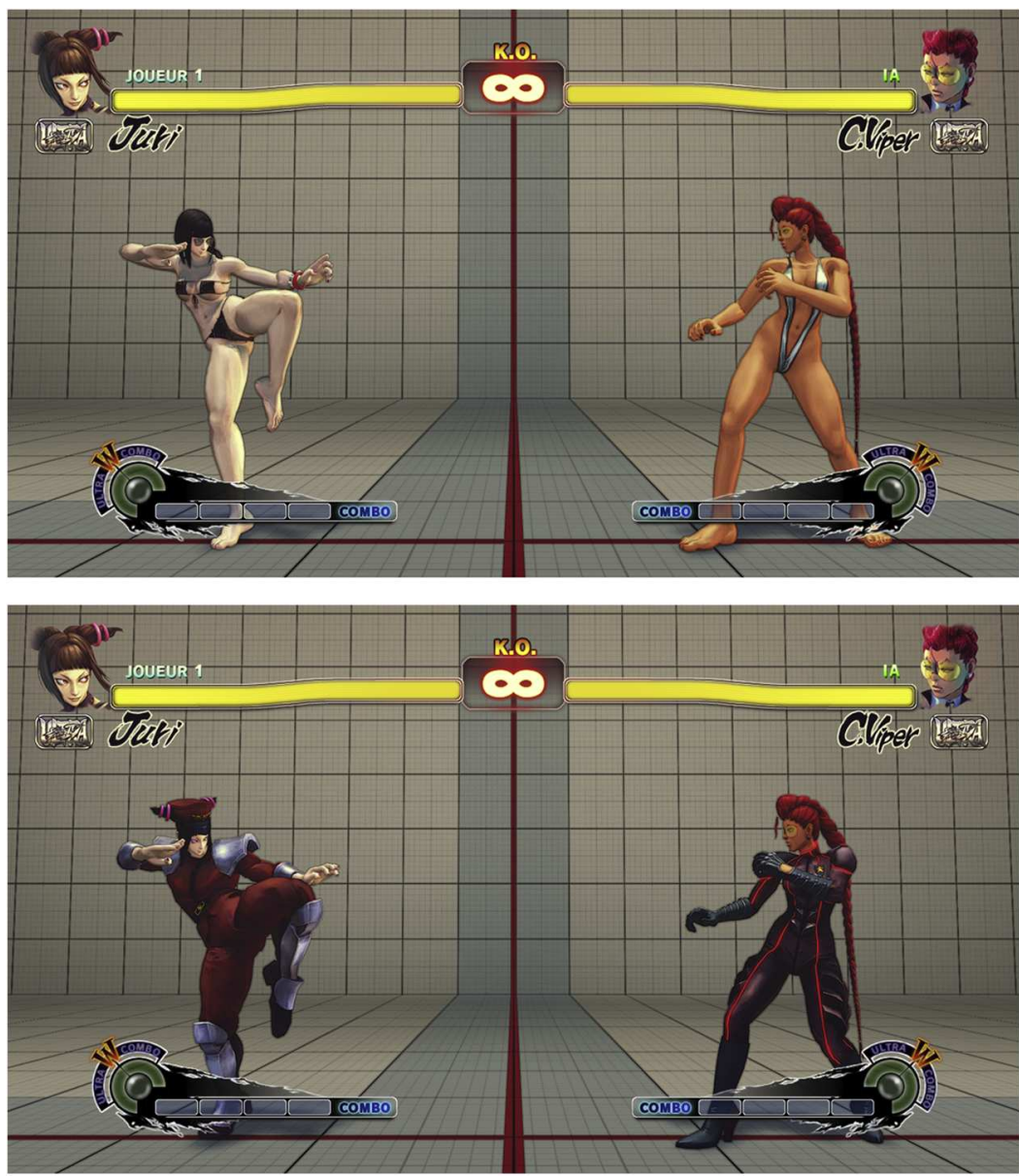

FIGURE 2 The top image is a screenshot of the sexualized video game condition, and the bottom image is a screenshot of the nonsexualized video game condition 


\section{3 | Questionnaires}

\subsection{1 | Demographic information and video game consumption}

Participants reported their gender and age. They also reported the average number of hours they spent playing video games each week, and their familiarity with the video game used in the present study.

\subsection{2 | Ambivalent sexism}

Participants completed a French version (Dardenne, Delacollette, Grégoire, \& Lecocq, 1996) of the Ambivalent Sexism Inventory (ASI; Glick \& Fiske, 1996), which contains an 11-item hostile sexism subscale (e.g., "Most women interpret innocent remarks as sexist; Cronbach $\alpha=.92$ ), and an 11-item benevolent sexism subscale (e.g., "Women should be cherished and protected by men"; Cronbach $\alpha=.84$ ). All items are scored using a 6-point response scale ranging from $0=$ Totally disagree to $5=$ Totally agree.

\subsection{3 | Trait aggressiveness}

Participants completed a French version (Genoud \& Zimmermann, 2009) of a short form of the Aggression Questionnaire (AQ; Bryant \& Smith, 2001), which contains 12 items (e.g., "I have threatened people I know") that are scored using a 6-point response scale ranging from $1=$ Not at all like me to $6=$ Completely like me $($ Cronbach $\alpha=.71)$.

\subsection{4 | Online disinhibition scale}

Participants completed a French version of the Online Disinhibition Scale (Udris, 2014), which contains 11 items (e.g., "The internet is anonymous so it is easier for me to express my true feelings or thoughts") that are scored using a 6-point response scale ranging from $1=$ Strongly disagree to $6=$ Strongly agree (Cronbach $a=.60)$. The scale was translated into French using the back-translation procedure.

\section{$2.4 \mid$ Procedure}

After giving informed consent, participants were told that they would participate in two separate studies about the impact of entertainment on psychological states-one on video games, and one on humor. First, they completed questions about demographics and video game consumption. Next, they were randomly assigned to play the sexualized or the non-sexualized version of the video game Ultra Street Fighter IV for $15 \mathrm{~min}$. The video game was played on a desktop computer with a 24-inch $(61-\mathrm{cm})$ screen and an Xbox controller. After gameplay, participants rated how difficult, fun, frustrating, exciting, competitive, realistic, and violent the video game was ( $1=$ Not at all to $10=$ Very much). The games did not significantly differ on any of these dimensions (see Table 1).

Next, participants were told that they would participate in the second study on humor with a partner. The "partner," who was in a
TABLE 1 t-test between the sexualized and the non-sexualized condition for video game experience

\begin{tabular}{llllllll} 
& $M_{s}$ & $\mathrm{SD}_{s}$ & $M_{\mathrm{ns}}$ & $\mathrm{SD}_{\mathrm{ns}}$ & $\boldsymbol{t}$ & $\boldsymbol{p}$ & $\boldsymbol{d}$ \\
Difficulty & 6.18 & 2.06 & 6.24 & 2.10 & 0.19 & .848 & 0.03 \\
Fun & 4.42 & 2.08 & 4.53 & 2.31 & 0.36 & .718 & 0.05 \\
Frustration & 6.48 & 2.74 & 6.49 & 2.47 & 0.04 & .968 & 0.01 \\
Excitation & 4.17 & 2.26 & 4.01 & 2.30 & -0.52 & .607 & 0.07 \\
Competition & 6.74 & 2.46 & 6.27 & 2.49 & -1.38 & .169 & 0.19 \\
Realism & 1.98 & 1.32 & 2.25 & 1.58 & 1.32 & .188 & 0.18 \\
\hline Violence & 7.07 & 1.98 & 7.00 & 2.22 & -0.23 & .818 & 0.03 \\
\hline
\end{tabular}

$\mathrm{df}=209 ; \quad s=$ Sexualized; $\mathrm{ns}=$ Non-Sexualized,$d=$ Cohen's standardized mean difference $d$.

different room, was actually an accomplice pretending to be another participant. The second study was used to measure whether the type of video game participants played influenced their sexual harassment of their "partner." The sexual harassment task was implemented using a Skype chat window, with the camera turned off. The participant had one Skype account. Two other Skype accounts were created for this study, one for the first experimenter (who interacted with the participant) and one for the accomplice who played both the partner and the second experimenter (who interacted with the partner). Manipulation of partner gender was carried out using the Skype pseudo. The female partner was called "Alexandra" (a common French female name) and the male partner was called "Alexandre" (a common French male name). The procedure consisted of five steps. First, participants were asked for their first name, which served as their Skype pseudo. Second, using the Skype chat, the experimenter pretended to ask the second experimenter if $\mathrm{s} / \mathrm{he}$ had already randomly selected which of the two participants was to be the sender of the jokes and which was to be the receiver of the jokes. Through a rigged lottery, the real participant was always "selected" to be the sender of the jokes by the second experimenter, whereas the partner was "selected" to be the receiver of the jokes. Participants were then told that their role was to send the jokes to their partner, and that we were only interested in their partner's response to the jokes. Third, to make the chat more realistic, participants were provided with five questions to ask their partner (i.e., "What is your gender?," "What is your age?," "What are you studying at university?," "Why did you choose this major?," and "What's your favorite TV show?"). The accomplice gave the standardized answers and asked the same questions to the partner. The gender question reinforced the name manipulation. Fourth, the participant was then shown the 16 slides, one at a time, and asked to send one of the two jokes to the partner on each trial. There were 16 trials, but only 8 of these trials contained a pair with a sexist joke. Thus, the number of sexist jokes sent could range from 0 to 8 . Fifth, the participant completed the personality questionnaires (i.e., the Ambivalent Sexism Inventory, the Aggression Questionnaire, and the Online Disinhibition Scale, in that order). A debriefing followed. During the debriefing, the experimenter probed to determine whether the participant was suspicious. 


\section{3 | RESULTS}

The first hypothesis was that the level of online sexual harassment behavior, especially toward women, will increase after playing a sexualized video game. Thus, we expected a two-way interaction between the type of video game participants played and the gender of their partner. This hypothesis was tested using a 2 (Sexualized video game vs. Non-sexualized video game) $\times 2$ (Male vs. Female Participant) $\times 2$ (Male vs. Female Partner) Analysis of Covariance (ANCOVA). Covariates included trait aggressiveness, hostile and benevolent sexism, and online disinhibition (Table 2). ${ }^{2}$ The ANCOVA revealed a significant main effect of participant gender and a significant main effect of partner gender. Male participants sent significantly fewer sexist jokes $(M=2.29$, $\mathrm{SE}=0.15)$ than female participants $(M=2.74, \mathrm{SE}=0.15)$. Male partners received significantly more sexist jokes $(M=2.13$, $\mathrm{SE}=0.15)$ than female partners $(M=2.89, \mathrm{SE}=0.15)$. This latter main effect was qualified by the predicted significant two-way interaction between type of video game and partner gender on sexist jokes (Figure 3). Planned contrasts revealed that being exposed to the sexualized video game (rather than the nonsexualized video game) significantly increased the number of sexist jokes sent to women, $[t(199)=2.28, p=.024, d=0.44]$, but did not significantly influence the number of sexist jokes sent to men $[t$ $(199)=-1.22, p=.222, d=0.24]$. Thus, the first hypothesis was supported.

A three-way interaction was used to test our second hypothesis, but it was not significant (see Table 3 for descriptive statistics for the experimental conditions). Thus, the second hypothesis was not supported.

Hostile sexism had a significant positive relation with sexual harassment $\left[F(1,199)=7.02, p=.009, \eta_{p}^{2}=.034, r=.19\right]$. All other main effects and interactions were non-significant. ${ }^{3} 4$

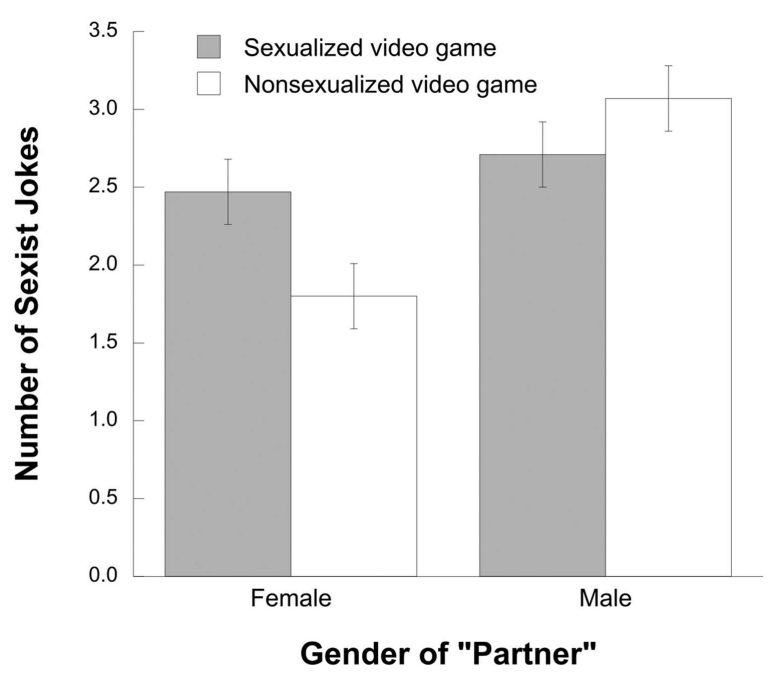

FIGURE 3 Interaction between exposure to sexualized media content and partner gender on the number of sexist jokes participants sent to their partner. Capped vertical bars denote 1 standard error

\section{DISCUSSION}

This study examined the specific impact of sexualized content of video games on online sexual harassment. To the best of our knowledge, only one other unpublished study has examined online sexual harassment using a behavioral measure (Tang, 2016). The present study also controlled for several individual differences that could be related to online sexual harassment, namely, hostile and benevolent sexism, trait aggressiveness, and online disinhibition.

Consistent with the first hypothesis, online sexual harassment was influenced by sexualization in video games. The significant two-way interaction showed that female sexualized video game content influenced online sexual harassment, but only toward female targets.

TABLE 2 ANCOVA on number of sexist jokes while controlling for general aggression, online disinhibition, hostile and benevolent sexism

\begin{tabular}{|c|c|c|c|c|}
\hline Source & $F$ & df & $p$ & $\eta_{p}{ }^{2}$ \\
\hline Sexualization & 0.56 & 1 & .455 & .003 \\
\hline Partner gender & 12.85 & 1 & $<.001$ & .061 \\
\hline Sexualization $\times$ partner gender & 6.13 & 1 & .014 & .030 \\
\hline Sexualization $\times$ participant gender & 0.26 & 1 & .612 & .001 \\
\hline Sexualization $\times$ partner gender $\times$ participant gender & 0.17 & 1 & .678 & .001 \\
\hline Hostile sexism & 7.02 & 1 & .009 & .034 \\
\hline Benevolent sexism & 2.16 & 1 & .144 & .011 \\
\hline Trait aggression & 1.84 & 1 & .176 & .009 \\
\hline
\end{tabular}


TABLE 3 Descriptive statistics for the experimental conditions

\begin{tabular}{|c|c|c|c|}
\hline \multirow[b]{2}{*}{ Participant gender } & \multirow[b]{2}{*}{ Partner gender } & \multicolumn{2}{|c|}{ Sexualization condition } \\
\hline & & $M(S E), n$ & $M(\mathrm{SE}), n$ \\
\hline \multirow[t]{2}{*}{ Male } & Male & 2.81 (0.29), 27 & $2.43(0.30), 26$ \\
\hline & Female & 1.71 (0.30), 25 & 2.19 (0.30), 26 \\
\hline
\end{tabular}

These results remained significant even after controlling for individual differences in hostile and benevolent sexism, trait aggressiveness, and online disinhibition. The second hypothesis was not supported (i.e., the effects were not larger for male participants than female participants). Both male and female participants sexually harassed a female partner more after they had played a sexualized video game.

\section{1 | Theoretical and practical implications}

The observed results are consistent with the integrated General Aggression Model (GAM) and Confluence Model of Sexual Aggression (Anderson \& Anderson, 2008). Sexualized content in video games is a sufficient situational variable to increase sexual harassment behavior. Female submissiveness might have been among the activated concepts related to both sexualization and sexual harassment. In addition, sexualization might have primed perceived humanness and agency. Previous research has found that when women are sexualized, they are also often dehumanized (Bernard et al., 2015; Puvia \& Vaes, 2013, 2015; Vaes, Paladino, \& Puvia, 2011). One cause of dehumanization is a lack of perceived agency (Lebowitz \& Ahn, 2016; Li, Leidner, \& Castano, 2014; Morera, Quiles, Correa, Delgado, \& Leyens, 2016; Tipler \& Ruscher, 2014). Furthermore, perceived agency and humanness of women are known to mediate the relationship between exposure to sexual media and sexually aggressive attitudes (Blake, Bastian, \& Denson, 2016; Rudman \& Mescher, 2012). Consistent with Expectation State Theory (Berger et al., 1972) and the Social Cognitive Theory of Gender Development and Differentiation (Bussey \& Bandura, 1999), the activation of stereotyped roles of women can explain the higher levels of sexual harassment of women. When the partner is a woman, participants will be more likely to sexually harass them due to the activation of concepts relating to female dehumanization, submission, and diminution of perceived agency.

An important contribution of these results to the video game research literature is that online sexual harassment behavior was provoked by exposure to sexualized female video game characters. This finding supports a number of studies that have found that sexualization, sexism, and sexuality in video games can influence sexual harassment (Dill et al., 2008; Driesmans et al., 2015; Yao et al., 2010). In addition, this study clarifies the results of past studies. Specifically, these results suggest that the sole presence of sexualized female characters (without the confounding influences of sexism or sexuality that were often involved in previous studies) is a sufficient condition to provoke online sexual harassment against females. Knowing that sexualization can influence negative behavior toward females is of primary importance, especially considering the large number of video games that contain female sexualized content (Beasley \& Collins Standley, 2002; Burgess et al., 2007; Downs \& Smith, 2010; Summers \& Miller, 2014).

To the best of our knowledge, this study is the first to examine sexual harassment toward men following exposure to sexualized female characters in video games. Sexualization of female characters does not seem to influence online sexual harassment toward men. Further, as shown by our main effect on partner gender, more sexist jokes were sent to men than to women. This unexpected result might be explained by the fact that men, as the dominant group, are not usually targets of sexual harassment and thus may be more tolerant of sexual harassment (Pina \& Gannon, 2006). Therefore, sexist jokes sent to men might be less likely to be identified as sexual harassment compared to sexist jokes sent to women.

Another unexpected result in this study was that female participants sent significantly more sexist jokes than male participants. This might be due to the fact that sexual harassment is perceived as usually committed by men, and toward women (Stop Street Harassment, 2018). Therefore, among our participants, women are likely to have experienced sexual harassment. Therefore, when sent to the in-group (i.e., another woman), it might be perceived as a simple joke, but when sent to a man, it might be perceived as a form of retaliation. Sexual harassment has been an important topic of discussion lately, notably with the \#MeToo movement. This may have increased awareness among men, which may have caused them to send fewer sexist jokes. Indeed, prevention campaigns about sexual harassment have been shown to reduce such behavior (Diehl, Glaser, \& Bohner, 2014).

Results from this study have important practical implications. We observed that exposure to sexualized females in video games increases online sexual harassment against female targets after the game is turned off. Sexual harassment is known to have deleterious consequences on women, such as reducing psychological well-being, satisfaction, commitment, and performance of the activity involving the harassment (Cantisano, Domínguez, \& Depolo, 2008; Pina \& Gannon, 2006).

Because sexualization might increase video game sales (Near, 2013), and because the video game industry is dominated by males, it is unlikely that the sexualized content of video games will be decreased 
in the near future. It is therefore important to educate players about the possible effect of exposure to sexualized female characters in video games on online sexual harassment. Parents should also limit the exposure of children and adolescents to video games with sexualized content. Further, prevention programs about the suffering of sexual harassment victims could be included in online video game environments. Indeed, such prevention strategies have been shown to reduce the likelihood of sexual harassment (Diehl et al., 2014).

\section{2 | Limitations and future research}

The results of the present study raise several questions that should be addressed in future studies. The main objective of this study was to examine the influence of sexualized female characters on sexual harassment. Women are most often the targets of sexual harassment (Stop Street Harassment, 2018). However, it would be very valuable if future studies also included male sexualized characters in order to examine how video game content influences sexual harassment against both men and women.

Future research should further investigate why participants sent sexist jokes to their partner. Especially in cases of more subtle forms of sexual harassment, the participant might not actually intend to sexually harass their partner. Motivations behind sexual harassment in general should be more researched because studies on this topic are scarce (McDonald, 2012). This study focused on online sexual harassment but it would be equally important to examine the extent to which observations from the present study also generalize to offline sexual harassment.

This study aimed to measure online sexual harassment behavior by using sexist jokes. However, this measure evaluated a specific form of gender harassment, rather than its global form. Future studies should try to replicate these results by evaluating the two other forms of sexual harassment, namely, unwanted sexual attention and sexual coercion.

One limitation of the present study is that it did not measure internal states. According to the GAM (Anderson \& Anderson, 2008; Anderson \& Bushman, 2002), the effects we observed should be mediated by internal states. For instance, one study found that playing a sexualized video game increased the occurrence of immediate sexual thoughts (Yao et al., 2010). Future studies could identify other such potential mediators related to the internal state evoked by sexualized video games, such as affects, arousal or other cognitions (e.g. perceived degree of agency and degree of humanness). Further, according to both the GAM and the Confluence Model of Sexual Aggression (Anderson \& Anderson, 2008), a large number of primary person variables can influence sexual aggression toward women. The present study controlled for several of these individual differences (i.e., hostile and benevolent sexism, trait aggressiveness, and online disinhibition). However, other Individual differences should be considered in future studies (e.g., gendered-stereotyped attitudes, dominant or submissive attitude).
By only manipulating sexualization, this study succeeded in suppressing confounding variables often found in other studies such as sexism and sexuality. However, one limitation of this study is that both the sexualized and non-sexualized video games contained violence, which could be considered to be a confounding variable. Future studies might address this limitation by explicitly distinguishing between sexualized content and violent content.

\section{5 | CONCLUSION}

These results help to contribute to a better understanding of the impact of sexualized video game characters on online sexual harassment toward women. Our results show that playing a video game with sexualized female characters increases online sexual harassment toward women. Sexual and general harassment are major problems in society, and video games depicting sexualized characters might be among the important underlying causes.

\section{ACKNOWLEDGMENTS}

The authors thank Clara Della Libera, Bénédicte Thonon, and Audrey Krings for reading a draft of the manuscript. The data are publicly available on Figshare and Dataverse.

\section{CONFLICTS OF INTEREST}

The authors have no conflicts of interest to declare.

\section{ENDNOTES}

${ }^{1}$ Using the Tukey fences method, we determined that 26 participants were outliers in terms of time spent playing video games. When these participants were excluded, the pattern of results was the same, except that the main effect of participant gender was no longer significant.

${ }^{2}$ The experimental manipulation (sexualized vs. nonsexualized video game content) did not influence any of the covariates. However, a main effect of participant gender was found for benevolent sexism, with males having higher scores than females. Further, a main effect of online disinhibition was found for partner gender, with participants feeling less disinhibited when their partner was a woman compared to when their partner was a man.

${ }^{3}$ Eleven participants expressed suspicion about the study, but the results did not change when they were excluded, except that the main effect of participant gender was no longer significant. Thus, we included all participants.

${ }^{4}$ We observed a "floor effect," with a median of two sexist jokes. The distribution was skewed to the right. However, the pattern of results was similar when the data were transformed to reduce skewness (using a logarithm method and a box-cox transformation), except that the main effect of participant gender was no longer significant. The results were also similar when we used nonparametric statistics (Mann-Whitney test) as when we used parametric statistics (ANCOVA). Thus, the results were quite robust. We report the untransformed data in this manuscript because the unit of measure is more intuitive. We also used parametric statistics rather than nonparametric statistics because they are more familiar to readers. 


\section{ORCID}

Jonathan Burnay iD http://orcid.org/0000-0002-7577-1454

Brad J. Bushman iD http://orcid.org/0000-0002-1266-5101

\section{REFERENCES}

Anderson, C. A., \& Anderson, K. B. (2008). Men who target women: Specificity of target, generality of aggressive behavior. Aggressive Behavior, 34, 605-622. https://doi.org/10.1002/ab.20274

Anderson, C. A., \& Bushman, B. J. (2002). Human aggression. Annual Review of Psychology, 53, 27-51. https://doi.org/10.1146/annurev. psych.53.100901.135231

Australian Bureau of Statistics. (2017). 8679.0-Film, television and digital games, Australia, 2015-16.

Beasley, B., \& Collins Standley, T. (2002). Shirts vs. skins: Clothing as an indicator of gender role stereotyping in video games. Mass Communication and Society, 5, 279-293. https://doi.org/10.1207/S153 27825MCS0503_3

Berger, J., Cohen, B. P., \& Zelditch, M. (1972). Status characteristics and social interaction. American Sociological Review, 37, 241-255.

Bernard, P., Gervais, S. J., Allen, J., Delmée, A., \& Klein, O. (2015). From sex objects to human beings: Masking sexual body parts and humanization as moderators to women's objectification. Psychology of Women Quarterly, 39, 432-446. https://doi.org/10.1177/0361684315580125

Blake, K. R., Bastian, B., \& Denson, T. F. (2016). Perceptions of low agency and high sexual openness mediate the relationship between sexualization and sexual aggression. Aggressive Behavior, 42, 483-497. https:// doi.org/10.1002/ab.21644

Brehm, A. L. (2013). Navigating the feminine in massively multiplayer online games: Gender in World of Warcraft. Frontiers in Psychology, 4, 1-12. https://doi.org/10.3389/fpsyg.2013.00903

Bryant, F. B., \& Smith, B. D. (2001). Refining the architecture of aggression: A measurement model for the Buss-Perry Aggression Questionnaire. Journal of Research in Personality, 35, 138-167. https://doi.org/ 10.1006/jrpe.2000.2302

Burgess, M. C. R., Stermer, S. P., \& Burgess, S. R. (2007). Sex, lies, and video games: The portrayal of male and female characters on video game covers. Sex Roles, 57, 419-433. https://doi.org/10.1007/s11199-0079250-0

Bussey, K., \& Bandura, A. (1999). Social cognitive theory of gender development and differentiation. Psychological Review, 106, 676-713. https://doi.org/10.1037/0033-295X.106.4.676

Cantisano, G. T., Domínguez, J. F. M., \& Depolo, M. (2008). Perceived sexual harassment at work: Meta-analysis and structural model of antecedents and consequences. Spanish Journal of Psychology, 11, 207-218. https:// doi.org/10.1017/S113874160000425X

Coombs, W. T., \& Holladay, S. J. (2004). Understanding the aggressive workplace: Development of the workplace aggression tolerance questionnaire. Communication Studies, 55, 481-497. https://doi.org/ 10.1080/10510970409388633

Dardenne, B., Delacollette, N., Grégoire, C., \& Lecocq, D. (1996). Structure latente et validation de la version française de l'Ambivalent Sexism Inventory: l'échelle de sexisme ambivalent. L'année Psychologique, 106, 235-264. https://doi.org/10.4074/S0003503306002041

Diehl, C., Glaser, T., \& Bohner, G. (2014). Face the consequences: Learning about victim's suffering reduces sexual harassment myth acceptance and men's likelihood to sexually harass. Aggressive Behavior, 40, 489-503. https://doi.org/10.1002/ab.21553

Dill, K. E., Brown, B. P., \& Collins, M. A. (2008). Effects of exposure to sexstereotyped video game characters on tolerance of sexual harassment. Journal of Experimental Social Psychology, 44, 1402-1408. https://doi. org/10.1016/j.jesp.2008.06.002
Dill, K. E., \& Thill, K. P. (2007). Video game characters and the socialization of gender roles: Young people's perceptions mirror sexist media depictions. Sex Roles, 57, 851-864. https://doi.org/10.1007/s11199007-9278-1

Downs, E., \& Smith, S. L. (2010). Keeping abreast of hypersexuality: A video game character content analysis. Sex Roles, 62, 721-733. https://doi. org/10.1007/s11199-009-9637-1

Driesmans, K., Vandenbosch, L., \& Eggermont, S. (2015). Playing a videogame with a sexualized female character increases adolescents' rape myth acceptance and tolerance toward sexual harassment. Games for Health Journal, 4, 91-94. https://doi.org/10.1089/g4h.2014.0055

Fredrickson, B. L., \& Roberts, T.-A. (1997). Objectification theory: Toward understanding women's live experiences and mental health risks. Psychology of Women Quarterly, 21, 173-206. https://doi.org/10.1111/ j.1471-6402.1997.tb00108.x

Galdi, S., Maass, A., \& Cadinu, M. (2014). Objectifying media: Their effect on gender role norms and sexual harassment of women. Psychology of Women Quarterly, 38, 398-413. https://doi.org/10.1177/0361684313515185

Genoud, P. A., \& Zimmermann, G. (2009). French version of the 12-item Aggression Questionnaire preliminary psychometric properties. Poster session presented at the 11th Congress of the Swiss Psychological Society. Neuchâtel, Switzerland.

Gervais, S. J., Bernard, P., Klein, O., \& Allen, J., (2013). Toward a unified theory of objectification and dehumanization. In S. J. Gervais, (Ed.), 60th Nebraska Symposium on Motivation (pp. 1-24). Nebraska: Springer.

Glick, P., \& Fiske, S. T. (1996). The ambivalent sexism inventory: Differentiating hostile and benevolent sexism. Journal of Personality and Social Psychology, 70, 491-512. https://doi.org/10.1037/00223514.70.3.491

Gray, K. L. (2012). Deviant bodies, stigmatized identities, and racist acts: Examining the experiences of African-American gamers in Xbox Live. New Review of Hypermedia and Multimedia, 18, 261-276. https://doi. org/10.1080/13614568.2012.746740

Jansz, J., \& Martis, R. G. (2007). The lara phenomenon: Powerful female characters in video games. Sex Roles, 56, 141-148. https://doi.org/ 10.1007/s11199-006-9158-0

Lebowitz, M. S., \& Ahn, W. (2016). Using personification and agency reorientation to reduce mental-health clinicians' stigmatizing attitudes toward patients. Stigma and Health, 1, 176-184. https://doi.org/ 10.1037/sah0000020

LeMaire, K. L., Oswald, D. L., \& Russell, B. L. (2016). Labeling sexual victimization experiences: The role of sexism, rape myth acceptance, and tolerance for sexual harassment. Violence and Victims, 31, 332-346. https://doi.org/10.1891/0886-6708.VV-D-13-00148

Li, M., Leidner, B., \& Castano, E. (2014). Toward a comprehensive taxonomy of dehumanization: Integrating two senses of humanness, mind perception theory, and stereotype content model. TPM - Testing, Psychometrics, Methodology in Applied Psychology, 21, 285-300. https:// doi.org/10.4473/TPM21.3.4

Lynch, T., Tompkins, J. E., van Driel, I. I., \& Fritz, N. (2016). Sexy, strong, and secondary: A content analysis of female characters in video games across 31 years. Journal of Communication, 66, 564-584. https://doi. org/10.1111/jcom.12237

Malamuth, N. M., Linz, D., Heavey, C. L., Barnes, G., \& Acker, M. (1995). Using the Confluence Model of Sexual Aggression to predict men's conflict with women: A 10-year follow-up study. Journal of Personality and Social Psychology, 69, 353-369. https://doi.org/10.1037/00223514.69.2.353

McDonald, P. (2012). Workplace sexual harassment 30 years on: A review of the literature. International Journal of Management Reviews, 14, 1-17. https://doi.org/10.1111/j.1468-2370.2011.00300.x

Miller, M. K., \& Summers, A. (2007). Gender differences in video game characters' roles, appearances, and attire as portrayed in video game magazines. Sex Roles, 57, 733-742. https://doi.org/10.1007/s11199007-9307-0 
Morera, M. D., Quiles, M. N., Correa, A. D., Delgado, N., \& Leyens, J. P. (2016). Perception of mind and dehumanization: Human, animal, or machine?. International Journal of Psychology, 12, 253-260. https://doi. org/10.1002/ijop.12375

Near, C. E. (2013). Selling gender: Associations of box art representation of female characters with sales for teen- and mature-rated video games. Sex Roles, 68, 225-269. https://doi.org/10.1007/s11199-012-0231-6

O'Hare, E. A., \& O'Donohue, W. (1998). Sexual harassment: Identifying risk factors. Archives of Sexual Behavior, 27, 561-580.

Pina, A., \& Gannon, T. A. (2006). An overview of the literature on antecedents, perceptions and behavioural consequences of sexual harassment. Personality and Social Psychology Review, 10, 252-264. https://doi.org/10.1080/13552600.2010.501909

Pryor, J. B. (1987). Sexual harassment proclivities in men. Sex Roles, 17 269-290. https://doi.org/10.1007/BF00288453

Puvia, E., \& Vaes, J. (2013). Being a body: Women's appearance related selfviews and their dehumanization of sexually objectified female targets. Sex Roles, 68, 484-495. https://doi.org/10.1007/s11199-012-0255-y

Puvia, E., \& Vaes, J. (2015). Promoters versus victims of objectification: Why women dehumanize sexually objectified female targets. International Review of Social Psychology, 28, 63-93.

Rudman, L. A., \& Mescher, K. (2012). Of animals and objects: Men's implicit dehumanization of women and likelihood of sexual aggression. Personality and Social Psychology Bulletin, 38, 734-746. https://doi. org/10.1177/0146167212436401

Russell, B. L., \& Oswald, D. (2016). When sexism cuts both ways: Predictors of tolerance of sexual harassment of men. Men and Masculinities, 19 524-544. https://doi.org/10.1177/1097184 × 15602745

Salter, A., \& Blodgett, B. (2012). Hypermasculinity \& dickwolves: The contentious role of women in the new gaming public. Journal of Broadcasting and Electronic Media, 56, 401-416. https://doi.org/ 10.1080/08838151.2012.705199

Shaw, A. (2011). Do you identify as a gamer? Gender, race, sexuality, and gamer identity. New Media and Society, 14, 28-44. https://doi.org/ 10.1177/1461444811410394

Siebler, F., Sabelus, S., \& Bohner, G. (2008). A refined computer harassment paradigm: Validation, and test of hypotheses about target characteristics. Psychology of Women Quarterly, 32, 22-35. https://doi.org/ 10.1111/j.1471-6402.2007.00404.x

Sinn, J. S. (1997). The predictive and discriminant validity of masculinity ideology. Journal of Research in Personality, 31, 117-135. https://doi. org/10.1006/jrpe.1997.2172

Stop Street Harassment. (2018). The facts behind the \#MeToo movements: A national study on sexual harassment and assault. Reston, VA. Retrieved from http://www.stopstreetharassment.org/wp-content/uploads/2018/01/FullReport-2018-National-Study-on-Sexual-Harassment-and-Assault.pdf

Summers, A., \& Miller, M. K. (2014). From damsels in distress to sexy superheroes: How the portrayal of sexism in video game magazines has changed in the last twenty years. Feminist Media Studies, 14 1028-1040. https://doi.org/10.1080/14680777.2014.882371

Tang, W. Y. (2016). An examination of specific situation and person factors in online video game sexual harassment. Ohio State University, Columbus, $\mathrm{OH}$. Retrieved from https://etd.ohiolink.edu

Tang, W. Y., \& Fox, J. (2016). Men's harassment behavior in online video games: Personality traits and game factors. Aggressive Behavior, 42, 513-521. https://doi.org/10.1002/ab.21646

Thompson, M. P., \& Morrison, D. J. (2013). Prospective predictors of technology-based sexual coercion by college males. Psychology of Violence, 3, 233-246. https://doi.org/10.1037/a0030904

Tipler, C., \& Ruscher, J. B. (2014). Agency's role in dehumanization: Nonhuman metaphors of out-groups. Social and Personality Psychology Compass, 8, 214-228. https://doi.org/10.1111/spc3.12100

Udris, R. (2014). Cyberbullying among high school students in Japan: Development and validation of the Online Disinhibition Scale. Computers in Human Behavior, 41, 253-261. https://doi.org/ 10.1016/j.chb.2014.09.036

Vaes, J., Paladino, P., \& Puvia, E. (2011). Are sexualized women complete human beings? Why men and women dehumanize sexually objectified women. European Journal of Social Psychology, 41, 774-785. https://doi. org/10.1002/ejsp.824

Vega, V., \& Malamuth, N. M. (2007). Predicting sexual aggression: The role of pornography in the context of general and specific risk factors. Aggressive Behavior, 33, 104-117. https://doi.org/10.1002/ab.20172

Williams, D., Martins, N., Consalvo, M., \& Ivory, J. D. (2009). The virtual census: Representations of gender, race and age in video games. New Media and Society, 11, 815-834. https://doi.org/10.1177/ 1461444809105354

Yao, M. Z., Mahood, C., \& Linz, D. (2010). Sexual priming, gender stereotyping, and likelihood to sexually harass: Examining the cognitive effects of playing a sexually-explicit video game. Sex Roles, 62, 77-88. https://doi.org/10.1007/s11199-009-9695-4

\section{SUPPORTING INFORMATION}

Additional supporting information may be found online in the Supporting Information section at the end of the article.

How to cite this article: Burnay J, Bushman BJ, Larøi F. Effects of sexualized video games on online sexual harassment. Aggr Behav. 2019;1-10.

https://doi.org/10.1002/ab.21811 